
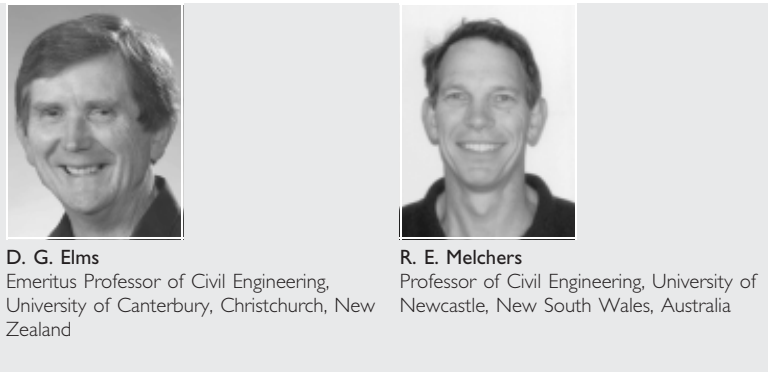

\title{
Assessing and achieving structural safety
}

C. B. Brown AKC, PhD, PEng, DistMASCE, D. G. Elms PhD, FRSNZ, DistFIPENZ and R. E. Melchers PhD, FICE, FIEAust, MASCE, FTSE

Structures seldom fail, so it is reasonable to conclude that they are 'safe' and that this state was attained in the processes of designing and building them. The process of achieving structural safety and the process of assessing whether structural safety has actually been achieved for a given structure are, however, two very different matters. This is the essence of this paper and the issues are discussed in terms of the four related topics of responsibility, failure, uncertainty and decision. The first deals with the domain of responsibility of structural engineers: what it is and what it should be and how this relates to structural failure. Four sources of failure are distinguished: technical, process errors, technical ignorance and various non-technical matters. The relative contributions of these are then discussed. Recent codes of practice have focused narrowly on technical uncertainty and a notional probability of failure, with little attempt to incorporate non-technical matters and the ontological uncertainty, which is shown to be the origin of most failures. Finally, the nature of decision making is discussed for both code development and structural design and it is concluded that in both cases the decision process is one of satisficing rather than optimising. The whole process is less rational than is generally supposed and requires a broader view in the outlook and training of structural engineers.

\section{NOTATION}

domain of consideration (all structures, some structures, one structure and so on), the universal set sub-set of D in which failures observed failures

the actual boundary between $\mathrm{F}$ and $\mathrm{S}$.

the estimate of $\mathrm{G}^{*}$

intersect of $\mathrm{F}$ and $\mathrm{E}$

notional concerns

the probability of the occurrence of $\mathrm{X}$

subset of D in which failures do not occur

failures owing to technical concepts

failures owing to technical errors

failures owing to non-technical matters

failures owing to technical ignorance

\section{INTRODUCTION}

As there are relatively few failures, it can be assumed that in general the safety of engineered structures is achieved. To achieve safety in any proposed structure it is conventional that the structural engineer considers whether a design satisfies the various criteria specified in codes of practice. The process seldom, if ever, involves the explicit consideration of the likely probability of failure of the structure that will result from the design and construction work. The assessment of safety, on the other hand, can be done in a variety of ways, but in a formal setting involves the estimation of the probability of failure for a proposed or an existing structure and ensuring that this probability is sufficiently low against a set of agreed criteria. In practice the probability of failure and the safety criteria may be measured by less formal surrogates. The safety level actually achieved is revealed by the statistics obtained from real data. Such achieved probabilities of failure are usually at least two orders of magnitude larger than the estimated or assessed values.

The present paper discusses the relationship between assessment and achievement. It argues that the relationship between the two is not at all clear, and concludes that structural engineers need a different and broader outlook than their training and employment currently provides. The paper is divided into four issues regarding structural safety. responsibility, failure, uncertainty and decisions. Each issue is considered in a separate section.

It is useful to begin by considering three figures (Figs 1-3). Here 'structure' is used quite generally and may be interpreted to include a structural element, a complete structure or even a group of structures. The regions in Figs 1-3 are more properly interpreted as 'sets' in set theory. The so-called 'universal set' is whatever is being discussed and is the domain D. It includes all reasonable forms, properties and dimensions the structure could have. This means that in the figures it includes sets $S$ and $\mathrm{F}$, that is, D is the union of $\mathrm{S}$ and $\mathrm{F}$, with the intersection of $\mathrm{S}$ and $\mathrm{F}$ being the empty set. $\mathrm{S}$ and $\mathrm{F}$ are separated by a boundary $\mathrm{G}^{*}$. This is the actual but unknown boundary and $\mathrm{G}$ in Fig. 2 is a professional estimate of $G^{*}$. In a world of complete certainty, as in Fig. 1, any structure defined by a point in $\mathrm{S}$ would have a probability of failure, $p_{\mathrm{F}}$, of zero and any structure in $\mathrm{F}$ a value of one. In the real world such certainty does not exist and a diagram in the form of Fig. 2 


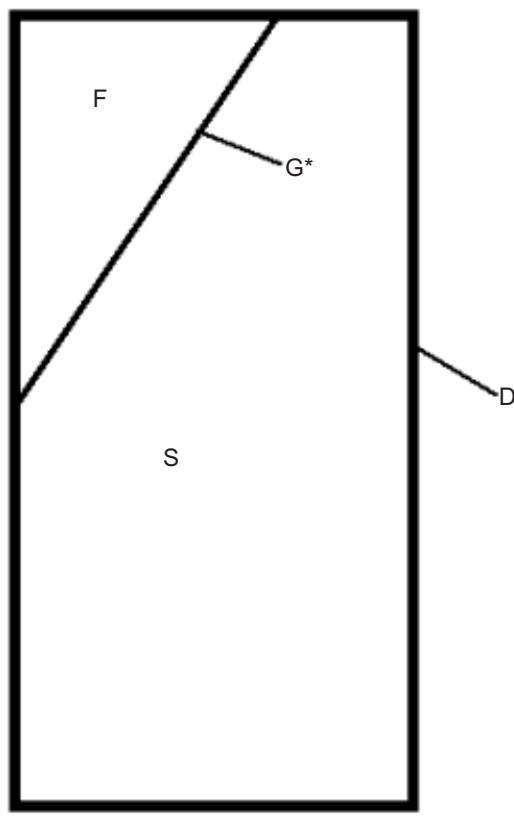

Fig. I. The Venn diagram shows the universal set as the domain $D$ divided into failed structures, $F$, and safe structures, S, with a common boundary $\mathrm{G}^{*}$

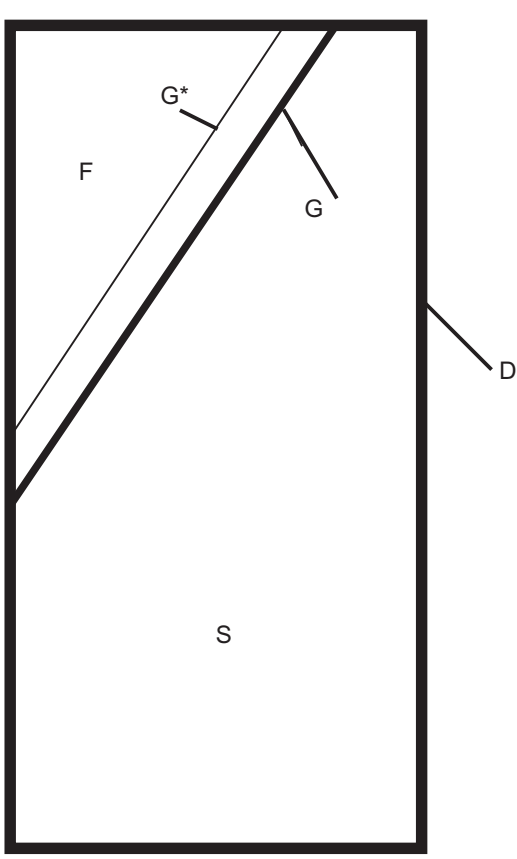

Fig. 2. The Venn diagram shows the universal set as the domain $D$ divided into failed structures, $F$, and safe structures, S. The actual boundary between $F$ and $S$ is $G^{*}$ and the estimated boundary is $\mathrm{G}$

begins to describe the situation. Here the boundary between $S$ and $\mathrm{F}$ is uncertain and this uncertainty is described by the probability of failure, $p_{\mathrm{F}}$, of a structure in $\mathrm{D}$ lying between zero and one. The boundary $\mathrm{G}$ indicates the professional estimate of the separation between $\mathrm{F}$ and $\mathrm{S}$ and the location of the feature relative to that boundary is an indication of its reliability. The

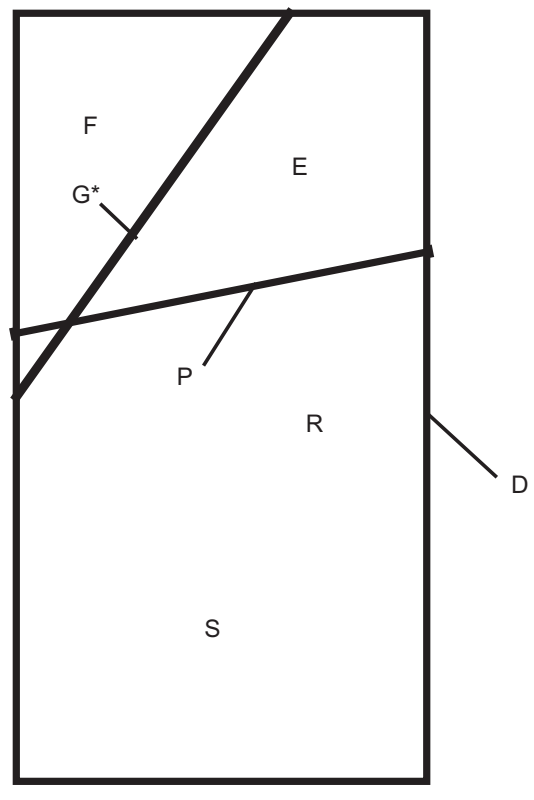

Fig. 3. The Venn diagram shows the universal set as the domain $\mathrm{D}$ divided in two ways between failed structures, F, and safe structures, $\mathrm{S}$, with a common boundary $\mathrm{G}^{*}$, and between structures which incorporate errors, $\mathrm{E}$, and those with no errors, $R$, with a common boundary $P$. $\mathrm{FUS}=\mathrm{EUR}=\mathrm{D}$

assessment of structural reliability concerns the analytical procedures that are necessary to estimate not only this value but also the credibility of this value. The achievement is concerned with the success of such assessment and hence level of safety in a real situation. The prescribed boundary, G, in Fig. 2 and the domain of discourse, D, are critical in the assessment. The domain, $\mathrm{D}$, is the collective features being discussed. D can, for example, be the bridges on a transportation system, the bridges of a certain type on the system, one of those bridges, or a member in such a bridge. What is being discussed, that is D, has to be sharply defined.

The domain, D, identifies the professional responsibility level of the decision. This is discussed in detail below in section 2, which considers a hierarchical range of domains that could determine the professional responsibility for the reliability within D. The sources of failure are defined and their combination identified from these considerations. To this stage little quantitative material has been introduced but with these sources of failure available, data corresponding to the sources are considered. Section 3 also includes explanations about errors and their effect on attaining safety. Fig. 3 shows the interplay between errors and safety together with the world of uncertainty exhibited in Fig. 2. This uncertainty includes the boundary between safe and unsafe structures, G, and the incidence of errors resulting in failure, the intersect of $\mathrm{F}$ and $\mathrm{E}$. Section 4 considers these matters. The background that has been established provides the basis for decision making. There is a tendency to think of this as design and to start a discussion on design codes. As different domains become the focus, however, it is apparent that decision making is perceived differently at different levels and at different times in the life of a structure. Certainly design, construction and codes have their place, but an understanding of the assessment of 
structural safety and the consequent achievement cannot be undertaken without broadening the discussion. Decisions are not only based on the chances of failure but also the consequences. The consideration of risk and the broadening of the considerations involved in structural safety are taken up in section 5. The four sections on responsibility, failure, uncertainty and decisions provide the background and context for a closing discussion on uncertainty and its relationship to structural reliability.

\section{RESPONSIBILITY}

Practicing structural design engineers have no difficulty in defining the domains of their work. Most are preparing designs of members and connections where safety is ensured by compliance to the relevant codes of practice. They are supervised within a larger domain where the intentions of the responsible engineer are enforced. That engineer also has responsibilities to satisfy the requirements of the owners. These are transmitted by architects, planners and other non-technical people. It is at this stage that this neat hierarchy of domains often breaks down and domains exist which call for engineers with understanding beyond the technical arena.

The various interacting domains do provide a process that leads to the preparation of bid documents, appointment of contractors, construction and acceptance by the owner. While structural engineers are active in design matters and contract preparation, the owner's interests are protected by the responsible engineers. The domain of the latter requires the understanding of the design, contract documents and the competency of the contractors, all intended to ensure that the structure is completed as designed.

Failures can occur at any stage and conditions can be generated in the design-construct process that can lead to subsequent failure. The concerns with respect to structural safety in this system are largely technical matters with which engineers may be assumed to be comfortable to the extent that their professional education and training has prepared them for this work. There is little doubt concerning the domain of activity of the various engineers and to whom they are responsible. Design-construction appears to be an orderly system in which the various activities seem to nestle like Russian dolls. Undoubtedly in practice many possibilities exist for failure to occur. Some can be associated with bounds in technical understanding having been transgressed and important information such as about material properties not being available. Let the probability of occurrence of such failures be termed $p_{\mathrm{T}}$.

A different cause of failure is undischarged responsibilities. This can occur through errors in the process. As an example, the flange width was confused with the web width in the design of the temporary structure of the Second Narrows bridge in Vancouver, Canada in 1958 and led to the collapse of the bridge during construction. The evidence to date suggests that the gusset plates were undersized on the Mississippi bridge in Minneapolis which failed in 2007, 40 years after construction. The reason for these failures can be considered technical but would not have happened without error. Herein such failure probabilities are termed $p_{\mathrm{TU}}$. The difficulty in assigning a cause is, however, well illustrated in the case of the
Mississippi bridge. Of course ignorance about technical matters can exist amongst practitioners and lead to technical failures. These are designated $p_{\mathrm{UT}}$. Pugsley ${ }^{1}$ pointed out that all technical work is influenced by non-technical factors which he termed 'climates'. They are

(a) new or unusual materials

(b) new or unusual methods of construction

(c) new or unusual types of structures

(d) experience and organisation of design and construction teams

(e) research and development background

$(f)$ industrial climate

(g) financial climate

(h) political climate.

Since then the list has been amplified but the point is that the neat, tidy domains associated with technical activities often have to be augmented to include such non-technical features. There are many known cases of structural failure associated with these psychological, organisational and sociological interactions. For instance an examination of 12 structures damaged in earthquakes indicated marked attenuation of safety in eight of them owing to such non-technical interactions. ${ }^{2}$ Herein the probability of failure of structures resulting from these non-technical matters is termed $p_{\mathrm{U}}$.

The broadening of discourse to domains that include disciplines that are unfamiliar to structural engineers can be difficult and yet participation in these extended domains is essential in the assessing and achieving of structural safety. Usually the interactions are with other professionals but the tendency to include all perceived stakeholders in discussions that involve structural matters requires an involvement with lay communities. For example, General Riley issued an edict requiring 'shared vision planning' in the civil arm of the US Corps of Engineers. ${ }^{3}$ In this way anyone who claims an interest in future civil engineering work by the Corps is invited to intrude into the planning and activation procedures. This is not a trivial matter as Riley supervises US $\$ 5$ billion annually of civil engineering work.

An expanded domain of interaction by engineers also brings out some other issues. For example, 'engineers' formal education seldom prepares them for wider roles. Moreover, the strident urging 'to think outside the box' can easily fall on deaf ears because it is not a part of the chosen career path and many employers do not actively encourage it. To deal competently with structural safety, however these broader domains leading to $p_{\mathrm{U}}$ have to be included. The process advocated by Riley would likely occur before the technical design and involve both qualitative and quantitative assessment by structural engineers, other professionals and a lay population. In practice it is this stage that reveals potential 'hidden' or 'forgotten' issues that may cause subsequent safety problems. In a more formal setting the interacting professionals can establish arrangements with definite responsibilities. Such discourses have to be conducted in a systematic manner with conclusions that identify responsibilities. A debate in itself, although often interesting, will not advance the achievement of structural safety. This broader discussion of the fundamental issues of safety is seldom conducted by structural engineering 
professionals even though there is a wealth of literature on the subject. $^{4}$

These four probabilities of failure can be considered as sub-sets on a Venn diagram where the universal set, F, is associated with the actual probability of failure. T, TU, UT and U have been defined such that the union is $\mathrm{F}$ and the intersect the empty set. Under these circumstances they are independent and the union operation then leads to the summation

$$
\quad p_{\mathrm{F}}=p_{\mathrm{T}}+p_{\mathrm{TU}}+p_{\mathrm{UT}}+p_{\mathrm{U}}
$$

This careful statement leading to independence does not attenuate the difficulty in assigning the appropriate sub-set for an actual failure.

The first three terms on the right-hand side of equation (1) represent work that falls under the authority of the responsible engineer (or engineer of record). This appears to be a clear and unambiguous responsibility. The breakdown of the technical part of the safety environment is, however often initiated by Pugsley's climates and other non-technical features. An example of this is the failure of the First Tacoma Narrows bridge in 1940 which initiated an exhaustive technical study of the behaviour of suspension bridges subjected to wind. At first blush the failure would be included under $p_{\mathrm{T}}$. However the picture changes when the history leading up to the failure is considered.

Funding for the structure was in the hands of the Washington Toll Bridge Authority which authorised the design of a structure. This design featured an $850 \mathrm{~m}$ central span with a $7 \cdot 6 \mathrm{~m}$ deep open truss stiffening beam. The span:depth ratio of 112 was typical of most bridges constructed since the Brooklyn bridge. The Authority then applied for monies to the Federal Public Works Administration in Washington, D.C., which agreed to provide $45 \%$ of the cost as long as a review board was established to examine the design. As a result, new designs of the super- and substructures were made, which were then constructed.

The superstructure consisted of the same span but was stiffened by two $2.43 \mathrm{~m}$ deep plate girders. The span:depth ratio was 350. It was this bridge that failed on November 7, 1940 and led to one of the most complete technical studies in structural engineering. The existing replacement bridge has the same span and a span:depth ratio of 85 ; the stiffening is with an open truss, $10 \mathrm{~m}$ deep. ${ }^{5}$ The failure is usually considered technical, but it can also be argued that the bridge was doomed once the original design was abandoned. The category defined by $p_{\mathrm{U}}$ would then be appropriate and the items of financial and political climates on Pugsley's list would have to be considered.

A domain of responsibility exists that is outside the technical and is identified with the climates of Pugsley. This domain requires understanding beyond that of technical matters and is a part of life in other endeavours. Those experiences and methodologies have been studied by Blockley ${ }^{6}$ and Henderson and Blockley ${ }^{7}$ within the philosophies of Popper and of Kuhn. Melchers ${ }^{8}$ has considered these non-technical matters from a systems view. The call is for decision makers to think outside the box' but there is as yet no clear, unambiguous responsibility for this extended vision of structural safety.

There is no trouble in believing that the assignments of responsibilities have been correct when things go well. It is only when confronted with failure that difficulties arise. Even when the failure is apparently due to technical reasons, as in the case of the Tacoma Narrows bridge, it may be possible to identify climates that ensured critical decisions that impacted the technical solution. In such circumstances it is not clear whether a T or a UT or a U type failure has occurred. For effective professional progress it is essential that a system exists that ensures that those with responsibility are at least aware of these circumstances while the design-construction operational sequence is underway.

\section{FAILURE}

The usual practice of design, construction and use anticipates that failures will occur. The codes of practice description of the loads, structural capacities and the boundary, G, in Fig. 2 are refined. There is, however, an abundant literature to show that failures are seldom the result of technical shortcomings. They are dominated by errors in design and construction, professional ignorance, and non-technical matters. Any collection of failure data will therefore tend to be describing $p_{\mathrm{TU}}, p_{\mathrm{UT}}$ and $p_{\mathrm{U}}$ rather than $p_{\mathrm{T}}$. A stronger statement can be made $^{8}$ that

$p_{\mathrm{F} 0} \approx p_{\mathrm{U}}$

where $p_{\mathrm{FO}}$ is the observed failure rate. The counting of the observed failures is usually arranged as statistics and they depend on the domain being considered. Some obvious domains are bridges, buildings and suchlike categories. Subdivisions can, however, also be informative. For instance, in the state of Washington five floating bridges have been built of which two have failed. In both cases the loadings surpassed the bridge capacities and the failures can reasonably be thought of as technical. This gloomy picture of $p_{\mathrm{FO}}=p_{\mathrm{T}}=0 \cdot 4$ has not dimmed the enthusiasm for this structural type inasmuch as a replacement for one of the three extant bridges is being completed which is also a floating bridge. Clearly this type of statistic is not taken too seriously by the owners and draws attention to requirements for the sample counted.

Certainly the numbers involved must be large enough and the sample truly representative of the population. These are largely subjective decisions even though helpful decision schemes can be employed. In the past such a congregation of data into domains has been treated very differently by different statisticians. For instance in the $19^{\text {th }}$ century the administrative statisticians in England had no trouble lumping all of the population together to identify public health concerns, whereas the French administrators baulked at such homogeneity on the premise that each French citizen was unique. ${ }^{9}$

More typical of structural safety is the observation by Fitzroy that the Beagle of Darwin fame was one of a class of 107 vessels of which 26 had capsized and one had been lost to enemy action. This count seemed to provoke Fitzroy to make changes to the vessel at his own expense, which improved its 
seaworthiness. ${ }^{10}$ The use of small sample sizes can, however, be misleading. De Moivre's equation relates variability to the sample size and unsatisfactory decisions have been made when possible wide variability associated with small sample sizes is ignored. ${ }^{11}$ One approach is to treat these data as 'data' in the singular, which exists as a basis for inference arguments, and not as a general 'fact'. Indeed arguments utilising data can lead to accepted facts.

There is an extensive literature to identify the causes of failures of various types of structure. ${ }^{12-14}$ These come to the uniform conclusion that the failure rate is two orders of magnitude greater than the notional probability of failure, $p_{\mathrm{N}}$, anticipated by the codes of practice. With little evidence that refinements in codes of practice make much difference to the chance of technical failures (G not crossing $G^{*}$ in Fig. 2), it has to be construed that the excess failures must be associated with $p_{\mathrm{TU}}$, $p_{\mathrm{UT}}$ and $p_{\mathrm{U}}$. These predominant causes of failures are lumped together in the literature as failures owing to errors, which are defined as departures from accepted practice as opposed to departures within accepted practice. Fig. 3 shows a Venn diagram which displays the occurrence of errors on the structures in the domain, D. D is divided in two ways: furst between failed, F, and safe, S, structures as in Fig. 1, with an unknown boundary between $\mathrm{F}$ and $\mathrm{S}$ of $\mathrm{G}^{*}$, and second between structures with and without errors, E and R, separated by the boundary $\mathrm{P}$. The intersect of $\mathrm{F}$ and $\mathrm{E}$ is termed $\mathrm{K}$ and represents the failed structures that incorporate errors and that between $\mathrm{F}$ and $\mathrm{R}$ the error free structures that failed. An indication of the importance of errors in assessing structural failure is that

$$
p_{\mathrm{T}} \ll p_{\mathrm{K}} \approx p_{\mathrm{FO}}
$$

A study of the incidence of error induced failures (K) results in some unambiguous statements, ${ }^{14}$ namely

(a) errors cannot be eliminated and are, at this time, largely unidentifiable before construction

(b) engineers and contractors are responsible for most errors; those by engineers are attributable to omissions in their professional preparation, experience and mistakes, and by contractors are a result of ignorance, neglect and thoughtlessness

(c) multiple errors are usually needed to produce failure.

An obvious source of errors is in the design calculations. Studies of checking of calculations ${ }^{15,16}$ show, however, that this is not a rich harvest. There appears to be little reward in eliminating design errors by the increase of checking time and costs. Little doubt exists that errors involve human behaviour ${ }^{17}$ and depend on professional environments. The following lists many disturbing professional practices

(a) inadequate experience of and rewards for design and field personnel, especially when novel structures are considered

(b) communication difficulties between the designconstruction-operation communities

(c) absence of scepticism about codes and calculations

(d) frequent personnel changes and compressed designconstruction schedules (e) practice and reality of cutting corners.

These practices show an overlap with the non-technical climates of Pugsley. ${ }^{1}$

It is not, however, apparent that the lay public has a clear understanding of risk in this sense. There is little evidence that the structural engineering profession is any better. The level of acceptance depends very much on the consequences of the failure. If not catastrophic, as is usual in structural failures, then the event will be tolerated more readily than a dramatic one. The combination of failure rate, owing to technical or error causes, and the consequences suggests that risk is the critical measure. The understanding of risk is, however, neither apparent in the public nor in the structural engineering profession. Certainly the public seldom discerns the difference between technical and error caused failures. Indeed there is no reason why it should. As with the professional engineer, it does not anticipate such errors and their occurrence is uniformly underestimated.

The chances of failure caused by technical shortcomings are small and in line with the expectation in design codes. Multiple errors in design, construction and operation provide the main cause of failure and are associated with non-technical environments. The technical environment abounds with the language of uncertainty (probability, statistics) and yet the consequences of technical work appear to be almost perfectly certain compared to the uncertainties of non-technical impacts on structural safety. Most failures are the result of nontechnical errors, which are seldom considered by practitioners and require consideration of uncertainty to achieve improved levels of structural safety.

\section{UNCERTAINTIES}

In Fig. 1 the structural domain is separated into two sets, safe $(\mathrm{S})$ and failed (F) separated by the boundary, $\mathrm{G}^{*}$. This is the world of complete certainty in which structural engineers would like to operate. It has, however, always been realised that uncertainties exist and the situation of Fig. 2 is accepted. Here $\mathrm{F}$ and $\mathrm{S}$ are uncertain and $\mathrm{G}$ is an estimate of the elusive $\mathrm{G}^{*}$. Early codes of practice made design provisions by specifying stresses that, when exceeded, led to failure and when respected resulted in safety. These limiting stresses provided for strength, deflections and stability concerns. The stresses specified had factors of safety built in of between 5 and 6 and F, S and G of Fig. 2 could be confidently treated as the F, S and $\mathrm{G}^{*}$ of Fig. 1. Designers therefore proceeded in a certain world in which they somehow felt 'protected' from disasters by safety factors which accounted for, amongst many features, ignorance, extreme loadings and strengths, and social implications. ${ }^{18}$

More recently uncertainties have gained some specific recognition in the design codes. This can be visualised by using the boundary G to estimate $\mathrm{G}^{*}$ in Fig. 2. Uncertainties in F, S and $\mathrm{G}$ are now considered and notional probabilities of failure described by reliability indices (the inverse of the coefficient of variation of the distribution of G). The intentions of the codes have, however, changed from attempting to include a broad coverage of structural safety to a narrower interpretation that concentrates on $p_{\mathrm{T}}$ alone as expressed by the notional 
probability of failure. ${ }^{19}$ Essentially an attempt to include a complete coverage of structural safety in codes has been replaced by greater precision about the technical aspects.

Most instruction in structural design considers ultimate failure and is based on load and resistance factor design (LRFD) codes. ${ }^{20}$ The two approaches to safety evident in earlier and contemporary codes are linked by the calibration of the latter to ensure the same structural performance as the earlier ones. By this calibration the present codes carry the non-technical implications of the predecessors into their target probabilities of technical failure. This puts the designer in the position of taking either approach and obtaining much the same resulting structure. As stated previously, the notional probability of failure approaches $p_{\mathrm{T}}$, which is a couple of orders of magnitude smaller than $p_{\mathrm{F}}$. This means that Fig. 2 only reveals a partial picture of the world of uncertainty. Fig. 3 is intended to complete the understanding and all that is omitted previously is explained by the region $\mathrm{E}$ on the structural domain, $\mathrm{D}$.

The region E covers errors of commission and omission. $p_{\mathrm{TU}}$ in equation (1) involves errors with respect to technical matters. These do occur: the misreading of steel tables and getting the statics wrong are examples of documented failures. $p_{\mathrm{UT}}$ covers failures caused by what the technical professional should know and yet does not employ. This form of ignorance, such as the ignoring of the lateral behaviour of suspension bridges, has occurred. Both $p_{\mathrm{TU}}$ and $p_{\mathrm{UT}}$ will be a continuing part of professional practice. They involve errors of commission and are collectively much smaller than failures due to errors of omission, $p_{\mathrm{U}}$, which involve non-technical matters that can be significant in structural failures.

Table 1 gives estimates of the time to design a tonne of structural materials in various types of structures. It provides an insight into these errors of omission. The structures of recent origin such as space craft, aircraft and offshore oil drilling structures require much more design time than structures with which there is a long experience. In such modern structures the question 'what can happen here?' as opposed to 'what did happen here?' has to be asked. In traditional structures there is an abundance of past experience to provide guidance. Without that experience there is a necessity to take into account a wider range of concerns than in traditional structures. This involves more time and contributes to the ordering in Table 1 . These broader concerns can reduce the uncertainties leading to $p_{\mathrm{U}}$. In the case of traditional structures broader concerns are generated by experience of surprising events. Examples are the Ronan Point failure and the subsequent concern for progressive collapse and

\begin{tabular}{|lc|}
\hline Structure & Design time: $\mathrm{h}$ \\
\hline Spacecraft & $4.5 \times 106$ \\
Aircraft & $9 \times 104$ \\
Offshore structures & 90 \\
$\quad$ Novel & 9 \\
$\quad$ Conventional & 6 \\
Bridges & 2 \\
Buidings & \\
\hline Table I. Design time for each tonne of structure \\
\hline
\end{tabular}

the Kings Street bridge failure and the concern about higher operational glassy temperatures in weld material. ${ }^{6}$

Of course, many of the troubles with spacecraft have not been beyond the understanding of more traditional structural engineers. Bits falling off and causing structural damage, details not functioning at operational temperatures and supplies, such as a telescope lens, being incorrect come to mind. There is an indication in Table 1 that considerations in novel structures will involve much more time with respect to the reliability associated with $p_{\mathrm{U}}$ than in traditional structures and that omission errors will be reduced. Certainly in professional situations where the avoidance of hazards is critical, such as in the nuclear power industry, the question 'what can happen here' dominates the discussion and the associated design time is high compared to that expected in buildings and bridges.

The uncertainty of Fig. 3 can be viewed in three ways, aleatoric (arising from statistical variation), epistemic (arising from modelling limitations) and ontological (to do with the difference between an engineer's assumptions and reality). ${ }^{21}$ Aleatoric uncertainty is about countable information available. This is often treated as random and arranged statistically. This information can be treated as data which are employed as the basis of inference and the establishment of models which allow significant generalisations beyond the a priori data to be generated. This modelling of data, which can enhance understanding of structural safety, composes epistemic uncertainty. The completeness of the data on which the inference is based is of critical importance and the domain of concern must be understood. Aleatoric and epistemic uncertainty are the main ingredients of contemporary codes of practice.

Epistemic uncertainty considerations are successful in assessing the technical part of failure, $p_{\mathrm{T}}$, in equation (1) and aleatoric uncertainty data provide an estimate of the combined $p_{\mathrm{TU}}$ and $p_{\text {UT }}$ contributions to failure. In equation (2), however, it can be observed that failures are largely caused by factors that are not considered in structural safety. These are omissions, that is factors which are not considered in structural safety, and commissions, that is actions that are in error and may range from simple mistakes to malicious acts. These errors of omission and commission fall under the umbrella of ontological uncertainty. It is here, as expressed by $p_{\mathrm{U}}$, that most failures originate and where little design time of conventional structures such as bridges and buildings is employed. Indeed, as pointed out in section 2, it is not evident where authority for such considerations lie.

The separations of uncertainty indicate that the reduction of $p_{\mathrm{U}}$ ensures the greatest increase in structural reliability. Table 1 shows the great design time put into spacecraft compared to other situations. One reason was the necessity of including all aspects that could reduce structural safety. This had to be done without past experience and the studies were dominated by problems of ontological uncertainty. Essentially the question was 'what can happen here?'. The same happened with aircraft in the first half of the 20th century. This changed with the introduction of the Messerschmitt BF 109 in 1935 which, with its monocoque metal body, retractable undercarriage and 
enclosed canopy, set the pattern for subsequent fighter planes. Over 30000 of these were built. ${ }^{22}$ From then on experience became available and the problems of such aircraft became codified. This codification occurred in traditional structures (buildings and bridges) at the beginning of that century.

With ongoing experience most eventualities could be provided for in revised codes of practice. The ontological uncertainty was only explored as new failure situations were observed. Examples are the impact of aircraft on structures, the drift of high rise buildings when masonry cladding was replaced by light weight cladding ${ }^{23}$ and vulnerable details after a significant earthquake. The question asked was 'what did happen here?' and only if the answer indicated novel safety concerns was there a move to broaden the studies. It would seem that in such structures acceptable levels of safety or economics have been achieved and there is little social and professional impetus to explore ontological uncertainty. One reason for an awakening interest may occur because of the success in reducing the death toll owing to structural failure in the technically advanced world. Deaths resulting from earthquakes and sea flooding have been reduced by orders of magnitude and the present concerns are about economic damage caused by structural failures. These concerns may stimulate a new effort to include ontological studies. ${ }^{7,24}$

In assessing and achieving structural safety both surprise and uncertainty about the results have to be minimised. They are not the same measures but it is only in the realm of uncertainty that surprise will flourish. This is not the same as searching for low probability environments. Although surprise has a low probability of occurring, not all low probability situations are surprising. ${ }^{25}$ An example is the absence of surprise, as opposed to gloom or pleasure, in any hand dealt in the game of bridge. The probability can be the same as a coin landing on its edge when tossed; an event which is surprising. It is sensible that studies on improving safety assessment concentrate on areas which have not been exhaustively considered, and may uncover surprises, and avoid focusing on issues which at best could deliver only very minor improvements. Inasmuch as $p_{\mathrm{U}}$ has much the same value as $p_{\mathrm{F}}$, it would be anticipated that most studies would concentrate on ontological uncertainty. Any reading of the literature shows, however, an emphasis in reducing the distance between $\mathrm{G}^{*}$ and $\mathrm{G}$ in Fig. 2. Elms ${ }^{26,27}$ has described a procedure to obtain consistent crudeness in understanding the various uncertainties evident in assessing structural safety. Any application of this theory of consistent crudeness can but justify the enthusiasm of Blockley to look "outside the box. ${ }^{6,7}$ Indeed the broader climates espoused by Pugsley over 30 years ago ${ }^{1}$ should still be dominant today.

\section{DECISIONS}

Professions have a common activity of making decisions in the face of uncertainty in a finite, limited period of time. The impact of the uncertainty and the time constraint make it likely that errors will occur. Structural engineering is no exception to this situation. Table 1 provides a sense of the relative time spent on designing different structures. In the cases of spacecraft and aircraft the design objectives can be different from the other structures listed. Both of these have design requirements of speed and acceleration as well as the pay load.
The power and fuel needed will depend on these and the vehicle weight. Newton's second law, $F=m a$, is the basis for the design decision which can be termed a minimum weight optimisation scheme. In this way the mass, and hence the power requirement, $F$, is minimised.

The other structural types listed in Table 1 are based on $F=0$ and optimisation with respect to weight has no attractions. There is a literature that advocates optimisation with respect to life time costs for such structures ${ }^{16}$ which demands the specification of the probability of failure, discount and interest rates, future costs and benefits, costs of failure involving legal obligations when there is a hint of error and conversions from money to utilities. Except for $p_{\mathrm{F}}$ these estimates of the future are influenced, if not dominated, by the musings of economists. Cost-benefit decision makers are often accused of justifying any previously decided course of action. This may be based on personal opinion introduced into these subjective specifications that model the future. If this is to be the course of decision making about structures then the work of Elms on consistent crudeness, ${ }^{26,27}$ whereby attention is directed to the features in the optimisation scheme that are least understood, is of importance. To the extent that optimisation with respect to costs and benefits occurs it is at levels of responsibility at which the structure is only one influential element. Structural failures can affect the operation but they are not the dominant concern of the decision maker. Worries about structural failures fall within the province of structural and geotechnical engineers where there exists a literature on formal analytical schemes ${ }^{20,28}$ that ensure consistency and order.

Risk involves a combination of the chances of a failure and the consequences. For precision the various economic forecasts in a cost-benefit scheme are required but, for a comparative study between locations and events, consistency can be more important. Thus the consequences of an earthquake in New Zealand may be considered ominous compared to the same earthquake in similar places in Australia or the USA. Among other matters, the impact of the event on the national economy and the critical nature of the location in that economy have to be included. These matters can often be assessed in a defendable manner and the balancing of risk between locations can be attained by changes in frequencies of occurrence in codes of practice and other institutional guides to professional practice. Consequential evidence may indicate preventative and also precautionary measures that reduce the chance of failures. For instance, retrofitting against earthquakes and the terminating of fatigue cracks by holes are preventative actions that reduce the chances of failure and use of sensing devices on structures is a precautionary action that give warning of structural changes. These are costly strategies which structural engineers may employ when justified by dire consequences of failure.

There appears to be a procedure by which professional decisions are made. This starts with a basic understanding of a broad field in which the topic (structure, legal case, patient) is embedded In a Bayesian model; this would be the a priori understanding. The particulars of the topic are then introduced and are analysed and argued about in the light of the earlier understanding. A decision is made in a finite time on the combined picture of the general and particular. Uncertainty 
exists in all these professional situations and the ontological part is of great importance. There is never a complete coverage of variables and possibilities. If errors are to be made in the decisions, they largely occur because of these omissions. An example is the identification of culprits in legal cases which subsequent DNA analysis showed to have been wrong.

Uncertainties have much in common from profession to profession. A medical internist and a geotechnical engineer examine the surface and obtain internal samples by biopsy or boring. These provide local internal evidence which have uncertainties of the aleatoric and ontological types. Decisions are made in the light of these uncertainties and the probability of occurrence enters the discussion. Legal trials in the EnglishAmerican system empower a jury to make decisions based on levels of probability that are different for civil and criminal cases. Here it is likely the understanding of probability is not that of axiomatic theory but is in terms of personal interpretation. It can be expressed in lay terms that make sense in a subjective framework. It is considered that this also has virtue in structural decision-making just as it has in legal situations. This power, in spite of shortcomings, has persisted for about a thousand years and does not seem likely to be supplanted. This suggests that it enjoys public and legal confidence even if the understanding of probability is a personal one. In much the same manner probability is not always used with precision in structural decision making.

Again it is likely that the understanding is personal and can be expressed in lay terms that make realistic sense. It has virtue in structural decision making as in legal ones. In this respect Cohen ${ }^{29}$ has argued that a Baconian view of probability in which the completeness of the evidence is graded, is applicable, as opposed to the Pascalian view where the evidence is complete. This separation of probabilities has a parallel to 'open' and 'closed' views of systems analysis. ${ }^{30}$ The open system includes matters that are outside the immediate environment of the considered problem and yet which might influence the outcomes in some, often undefined, manner. The closed system is amenable to the axiomatic constraints of probability theory but requires a complete specification of alternatives. With openness an inclusion of matters that have to be considered in assessing UT and U failures is possible but the comfort of precise assessment values is lost. With a closed situation the problem is well defined and the results sharp. It is well suited to avoiding $\mathrm{T}$ type failures. Both approaches to probability can have a place in structural reliability.

Decisions are made in structural design in two stages. The responsible engineer decides about the structural system. In the case of buildings the architect usually has defined what is possible and the engineer has less control than in bridges. The relative control in decision making may explain the design time shown in Table 1. Additionally the value of the structure in a building (about 15\% in a high rise one) is smaller than in a bridge. The decision by the responsible engineer is an iterative process which can be likened to painting a picture. The start is with a blank sheet of paper and the final scheme is determined by trial and error, an understanding of alternatives, materials and objectives, and a synthetic ability. In the end a decision on the final scheme is made and the work of proportioning members and connections commenced. This is the second design activity and today is governed by codes of practice and in the earlier days by a protocol established by the design firm.

For much of the design both by the responsible engineer and by the design staff, the process can be thought of as satisficing rather than optimising. Formal decision making is organised into the establishment of alternatives that satisfy objectives and constraints, and criteria that allow the selection of the best alternative. The claim of satisficers ${ }^{31,32}$ is that the human mind is incapable of modelling all significant practical problems; the alternatives, objectives and constraints are incomplete and a formal decision process cannot produce global answers. To solve real-world problems, solutions that are acceptable to the stakeholders are advised. The seeking of acceptable as opposed to best solutions is termed satisficing. In architecture it has been claimed that the best facility is the one with the least problems or conflicts. ${ }^{33}$ The uncertainties previously discussed indicate that there are good reasons why satisficing is what much of structural design, like architecture, is about. ${ }^{34}$ This means that the search for a design that satisfies various wishes such as safety, resilience, durability and an insensitivity to changes of variables and parameters, can better describe structural decision making than one that seeks to optimise. Indeed, the establishment of a satisficing environment is evident in codes. Table 2 shows the annual frequency of failure implications of Australian and New Zealand codes for wind, earthquake and snow loading. ${ }^{35}$ At first sight it seems strange that there is no consistency in notional probability of failure either between the loadings or, for earthquake and snow loadings, between countries. The codes are not balanced either internally or between each other. The values of $p_{\mathrm{T}}$ are inconsistent. The issue is significant and warrants further discussion.

To begin with, all failures are not equal. Failures owing to wind, earthquake and snow have different characteristics and different economic and community implications. A recounting of some of these differences in engineered structures is instructive.

(a) Earthquakes produce total structural failures, wind and snow predominantly produce local failures of roofs.

(b) Earthquakes strike without warning whereas heavy snow loads and high winds are more predictable.

(c) Damage caused by earthquakes is likely to be more severe with respect to the local infrastructure than due to wind and snow. Serious damage and disruption to water supply

\begin{tabular}{|lrrr|}
\hline \multirow{2}{*}{ Design life: years } & \multicolumn{3}{c|}{ Annual frequency of exceedence } \\
\cline { 2 - 4 } & Wind & Earthquake & Snow \\
\hline \multirow{2}{*}{25} & $1 / 1000$ & $1 / 250$ & $1 / 1000$ \\
& $1 / 1000$ & $I / / 000$ & $I / 250$ \\
50 & $1 / 2500$ & $1 / 500$ & $1 / 2500$ \\
& $I / 2500$ & $I / 2500$ & $1 / 500$ \\
& & & \\
& & & \\
Table 2. Intended annual frequency of exceedence of \\
Australian and New Zealand (italics) code provisions
\end{tabular}


and transportation is demonstrably more likely caused by earthquakes than by wind and snow.

(d) The time to recover from earthquakes and wind is longer than from snow storms. As a result of these economic differences and the extent and duration of the three disasters, the subsequent functioning of the communities will be different.

(e) The threat to life is high in earthquakes, moderate in winds and low in snow storms.

In reaching their decisions, code committees have to bear these issues in mind. Besides these differences in the nature and consequences of failures, there are other issues including

(a) the need to calibrate new codes to previous successful and accepted practice, which, in turn, could be seen as an encapsulation of experience

(b) response to previous failures, especially recent ones, and the recommendations of commissions of inquiry

(c) pressures from industry and professional groups

(d) the tendency of regulators to make regulations more

stringent than previous ones and of code writers to make codes even less stringent, both without compelling reasons

(e) a general and appropriate desire to feel comfortable about the results.

This Pugsleyan listing makes it scarcely surprising that code requirements display apparent inconsistencies. Clearly the design process is one of satisficing rather than optimisation. Two questions do, however remain

(a) could the codes be better?

(b) should their values be consistent?

A second issue arising from the apparent inconsistencies in Table 2 is the relationship between $p_{\mathrm{N}}$ and $p_{\mathrm{T}}$. Elsewhere it has been stated that the probabilities converge and tend towards common values. This may not be for a teleological reason. The notional probability is a mental construct whereas the probability of technical failure is a real, if elusive occurrence. $p_{\mathrm{N}}$ is determined for reasons that are ill defined and often unstated such as the reduction of surprise and avoidance of failure when errors exist. On the other hand, $p_{\mathrm{T}}$ is difficult to separate from the three other failure probabilities and to all intents and purposes impossible to measure in practice. A reason for this convergence could be that $p_{\mathrm{N}}$ tacitly defines the average $p_{\mathrm{T}}$ for a class of structures and within this class the range of $p_{\mathrm{T}}$ depends on the level of refinement of the code. Thus as codes 'improve' the best estimate of $\mathrm{G}^{*}$, it approaches closer to G in Fig. 2.

\section{DISCUSSION}

Over the life of a structure decisions are made that may involve planning, design, bidding and acceptance, construction, acceptance, operation, maintenance, rehabilitation and changes and removal. As these stages progress the chances of failure alter. ${ }^{8}$ Until actual construction is underway failure is in the mind rather than a reality. Over the rest of the life failure can, however, occur; the chance of failure changes with time and depends on the ownership. The owner of a highway system or a retail chain has a different responsibility for life use of a structure than a developer. In the first situation society is somewhat protected against failure by the continuing interests of the owner, whereas, in the second situation the protection may be shared with local public authorities. In either situation continual vigilance and assessment are essential ingredients in achieving structural reliability.

Failures can be divided into two classes: one confined to an individual structure and one, such as an earthquake or act of war, that affects many structures. In the first case the ideas of the previous paragraph prevail and although the loss may have a wide impact, the ownership is specific and isolated; the remedy is local. In the second case the losses and ownership are wider. The responsibilities are different in the two situations and the domain, D, has to be viewed differently. The professional efforts with respect to the individual structure have been dominated by the saving of lives. This is certainly of interest when considering the many structures affected by the wrath of nature and war, but additionally the broader impact on the economics and social arrangements have to be included. Here structures which have been damaged are often as important as those that have collapsed. The remedies are seldom local and demand the resources of a much wider community, usually by means of taxes and levies. This intrusion of politics and other topics of the social sciences ensures that the climates of Pugsley ${ }^{1}$ are explicitly important in the achieving of structural safety. The existing arrangements for attaining safety over the lifetime of individual structures appear to be satisfactory to the profession and to society as whole. The failure rates and consequent loss of lives do not appear out of line with the normal dangers of everyday life and do not inspire public outcries. Professional endeavours to improve this form of structural safety tend to concentrate on technical matters to reduce $p_{\mathrm{T}}$ and to shift $\mathrm{G}$ closer to $\mathrm{G}^{*}$ in Fig. 3. There is no doubt that this professional work has been successful.

Concerns about the safety of individual structures have usually been due to surprising phenomena and the increase of $p_{\mathrm{U}}$. Once displayed such a new phenomenon receives intense, and often over enthusiastic, professional attention and acceptable levels of safety quickly result. Where many structures are involved there is a shorter history of professional experience. Riley ${ }^{3}$ has ordered the inclusion of all stakeholders into the discussions of future civil work of the US Corps of Engineers. In the case of the effects of earthquakes and flooding this would include medical and transportation professionals as well as those providing power, fure protection, rescue and other services. There is certainly a place for structural engineers in these deliberations and from the discussion of Table 2 it is clear that they have responded to these widespread events by the local requirements for safety.

It is not, however, clear how structural engineers will be placed in the integrated planning and decision making. It is certainly a time for the professional institutes to take a leadership role. This should at least include an extensive non-technical interplay with professional institutions whose membership have a stake in the decisions and, more likely, the subjection of individual institutional authority to broader communities such as the national academies.

A virile profession requires a continual environment of change. 
This is the case with structural engineering. For instance, changes in the construction, the continual assessment of structural performance and the monitoring of structural behaviour are documented. ${ }^{36-38}$ There are also changes in professional environment which may be subtle but effective. One is the impact of commercialism into professional life where pressures, other than those traditionally accepted in practice, appear in the workplace. These are novel situations and Pugsley's list is particularly applicable. The institutions have to be unambiguous in their concerns about the effects of changes in practice in achieving structural reliability. One source of information is the informed and valid whistleblower. When such accounts are proved correct, the professional institutions should protect the informants. This could mean a change from past policies. ${ }^{39}$

The place of errors in assessing and achieving structural safety, as indicated by equation (2), has been significant. An acceptance of human failings that lead to errors exists in the population. ${ }^{40}$ This generosity is more evident when the consequences are not serious. Fortunately most structural failures are local with limited consequences and public blame is seldom displayed. Optimism is the order of the day with respect to most human endeavours and structural engineering is no exception.

An essential aspect in achieving structural safety is the combination of quantitative and qualitative insights. Something can be learned from the risk assessment methods conventionally practiced in hazardous industries. Before considering chances or consequences the question "what can or could go wrong?' is addressed. The answer probes into past experience and is an attempt to discern reality. Professionals from all relevant disciplines are at the table. In the case of a bridge these would at least include staff functioning in design, construction, maintenance and operation. This is a stage when experience is truly valued and where 'forgotten' events can be revealed..$^{40}$ The subsequent decisions will rest heavily on this preamble.

An example of the importance of ascertaining real world scenarios is cited by Stephens ${ }^{41}$ when concerned with the unintended launching of nuclear tipped missiles. The considerable confidence obtained in initially estimating on the basis of paper constructs the safety of the system was squashed when the real evidence of experience was included. The procedure of determining what was in reality known before proceeding with calculations provided confidence in predicting behaviour. This separation of design into these two parts, the search for what is known and the actual production based on contemporary codes, can be related to Fig. 2. The search for reality is an attempt to identify locations near or on $\mathrm{G}^{*}$. The actual production is an attempt to provide a structure located inside G. The first part can help ensure that available evidence from the past is not overlooked and that UT type failures do not occur.

Basically, to deal with the non-technical sources of error by structural engineers requires a different outlook and a different training. Perhaps the tasks and roles of the structural engineer need to be revisited, and here Blockley may be suggesting a way with his advocacy of 'doing it differently'. ${ }^{42}$
Encouragement is found in the work of the Standing Committee on Structural Safety (SOCC $)^{43}$ and the emphasis on 'soft management' issues. This view is espoused from a business and industry perspective, which could augment the professional concern of this paper and the discussions and rejoinder to Melchers' study (Ref. 8). ${ }^{44}$

The independence between T, TU, UT and U is important in this discussion on structural safety. These definitions of the causes for failure were introduced by Melchers et al. ${ }^{45}$ and their relationship, as displayed in equation (1), in Ref. 8. The use here emphasises the importance of ensuring that the considerations of errors has been complete. Comparison of this work with ideas in another field at another time is of interest. In 1689 John Locke ${ }^{46}$ stated the roots of human error as
(a) want of proof
(b) want of ability
(c) want of will
(d) wrong measures of probability.

In this paper the roots of errors of commission and omission are

(a) TU, of a technical nature

(b) UT, associated with technical ignorance

(c) U, caused by events outside the professional environment.

The first two in each of these lists can be construed as equivalent. The want of will is apparent in the efforts needed to avoid technical errors, overcome ignorance and to be involved in matters beyond the technical realm. Over 200 years ago probability measures were tied to the likelihood of a fact or idea being true in the light of evidence and did not demand completeness. They were open systems. Today the meaning is applied to a closed system and supported by the axiomatic definition of mathematics. Two types of error can be identified from Locke's last root, omission of evidence and exclusion of alternative facts and ideas. These were certainly the overwhelming concerns with respect to U type errors discussed here. It is claimed that the broad view of this paper covers the various origins of errors.

\section{CONCLUSIONS}

Technical matters are the province of structural engineers. Codes are relied on for the avoidance of technical failures, $\mathrm{T}$. A quality assurance process must, however, be in place to ensure that the codes are followed. This is the responsibility of civic and state authorities as well as an internal imperative for an engineering firm. The aim is to ensure that in effect technical failures are virtually impossible.

Errors dominate the ability to assess and achieve structural safety. Three categories are evident.

(a) TU, technical errors; again a checking process must be in place and applied to even minor structural parts. Failure of minor parts can have great financial consequences; here the Hyatt Regency Hotel failure and the Mississippi bridge in Minneapolis collapse are prime examples. These are matters for the professional engineer and can be reduced 
by changing managerial arrangements and require additional professional resources.

(b) UT, errors of ignorance about technical matters; these require the individual continuing study and the time and opportunity for such study if this personal professional ignorance is to be reduced. The responsibility here is with the individual, the professional management and the professional institutes. Errors of this type can apply to the profession as a whole, for example, when shortcomings in codes of practice are suddenly revealed by previously undisplayed failure modes. Codes are quickly modified to remedy this error. The professionals involved in code writing have responsibilities not only to respond to these sudden events but also to anticipate them. This may require examination of broader issues at the expense of attaining greater precision. Certainly when new or different ventures are considered the climates of Pugsley ${ }^{1}$ must be incorporated. This requires the professional environment and training to be much extended.

(c) U, errors of ignorance of the impact of non-technical matters on structural safety. The main professional thrust has to be the avoidance of surprise. Most failures can be assigned to this source and yet there are seldom existing organisations to provide the necessary extra-mural insights. To reduce surprise requires the leadership of professional institutes which must be actively involved with non-engineering communities. Such involvement will provide insight to others on the role of engineers and a professional understanding of the external impacts on structural safety. The dissemination of this understanding is in the lap of professional institutes.

The relationship of these errors to the assignment of responsibilities, modes of failure, uncertainty and the making of decisions comprises the body of the work. To broaden the consideration of safety it will be necessary to enlarge the understanding of professional engineers so that they are aware of the ideas and vocabularies of contributing disciplines.

\section{REFERENCES}

1. Pugsley A. C. The prediction of proneness to structural accidents. Structural Engineering, 1973, 51, No. 6, $195-$ 196.

2. BRown C. B., JohnSon J. L. and Loftus J. J. Subjective seismic safety assessments. Journal of Structural Engineering, American Society of Cvil Engineers, 1983, 110, No. 9, 2212-2233.

3. RILEY D. Shared Vision Planning. Memo to District and Battalion Commanders, United States Corps of Engineers, 2007.

4. ConRAD J. (ed.) Society,Technology and Risk Assessment. Academic Press, London, 1980.

5. ANDREWS C. E. Final Report on the Tacoma Narrows Bridge. Report to the Washington Toll Bridge Authority, Olympia, Washington, USA, 1952.

6. BLOCKLEY D. I. The Nature of Structural Design and Safety. Ellis Horwood, Chichester, 1980.

7. Henderson J. R. and BlockLeY D. I. Structural failures and the growth of engineering knowledge. Proceedings of the Institution of Civil Engineers, Part 1, 1980, 68 (November), 719-728.

8. MELCHERS R. E. Structural reliability theory in the context of structural safety. Civil Engineering and Environmental Systems, 2007, 24, No. 1, 53-69. (See also Discussion and rejoinder in Ref. 44).

9. SCHWEBER L. Disciplining Statistics. Demography and Vital Statistics in France and England 1830-1885. Duke University Press, Durham and London, 2006

10. BRENT P. L. Charles Darwin: A Man of Enlarged Curiosity. W. W. Norton, New York. 1981.

11. WAINER H. The most dangerous equation. American Scientist. 2007, 95, No. 5, 249-256.

12. MelChERS R. E. Structural reliability assessment and human error. Reliability and Risk Analysis in Civil Engineering. Proceedings, ICASP-5. Institute of Risk Research, Vancouver, 1987, Vol. 1, pp. 46-54.

13. NovaK A. S. (ed.) Modeling human error in structural design and construction. Proceedings of a National Science Foundation Workshop, Ann Arbor, 1986.

14. BRoWN C. B. and YIN X. Errors in structural engineering. Journal of Structural Engineering, American Society of Civil Engineers. 1988, 114, No. 11, 2574-2593.

15. Melchers R. E., Harrington M. and Stewart M. G. Human error in structural reliability. Civil Engineering Reports 1-V. Monash University, Australia 1983-1985.

16. MelChers R. E. The influences of control processes in structural engineering. Proceedings of the Institution of Civil Engineers, 1978, 65,No. 2, 791-807.

17. Reese R. C. Structural failures from the human side. Civil Engineering, American Society of Civil Engineers, 1973, 43, No. 1, 81-84.

18. Brown C. B. Concepts of structural safety. Journal of the Structural Division, Proceedings of the American Society of Civil Engineers, 1960, 86, No. ST-12, 39-57.

19. ELISHSKOFF I. Safety Factors and Reliability: Friends or Foes? Kluwer Scientific Publications, Dordrecht, 2004.

20. Melchers R. E. Structural Reliability, Analysis and Prediction. Ellis Horwood, Chichester, 1987.

21. ELMS D. G. Structural safety: issues and progress. Progress in Structural Engineering and Materials, 2004, 6, No. 2, $116-126$.

22. Glancey J. Spitfire. The Biography. Atlantic Books, London, 2006.

23. Wood R. H. The stability of tall buildings. Proceedings of the Institution of Civil Engineers, 1958, 11, 69-102.

24. BRown C. B. and Elms D. G. Structural design codes of practice and their limits. International Journal of Risk Assessment and Management, 2007, 7, No. 6/7, 773786.

25. WEAVER W. Lady Luck. The Theory of Probability. Anchor Books, Doubleday \& Company, Garden City, New York, 1963.

26. Elms D. G. The principle of consistent crudeness. Proceedings of the NSF Workshop on Civil Engineering of Fuzzy Sets. Purdue University, 1985, pp. 35-44.

27. Elms D. G. Consistent crudeness in system construction. Optimisation and Artificial Intelligence in Civil Engineering (TopPING B. H. V. (ed.)). Kluwer Scientific Publications, Dordrecht, 1992, Vol. 1, pp. 61-70.

28. JoRdaAn I. J. Decisions under Uncertainty. Probabilistic Analysis for Engineering Decisions. Cambridge University Press, Cambridge, 2005.

29. CoHen L. J. The Probable and the Provable. Clarendon Press, Oxford, 1977. 
30. Stewart M. G. and Melchers R. E. Probabilistic Risk Assessment of Engineering Systems. Chapman \& Hall, London, 1997.

31. Simon H. A. Models of Man, Social and Rational: Mathematical Essays on Rational Human Behavior in Social Settings. Wiley, New York, 1957.

32. Simon H. A. Administrative Behavior, $2^{\text {nd }}$ edn. Free Press, New York, 1957.

33. AleXAnder C. J. Notes on the Synthesis of Form. Harvard University Press, Cambridge, 1964.

34. Brown C. B. Optimizing and satisficing. Structural Safety, 1990, 7, 155-163.

35. REID S. G. Design differentiation for critical infrastructure networks for disaster mitigation. IFED07, Shoal Bay, Australia, 2007.

36. Dester W. S. and BlockLey D. I. Managing the uncertainty of unknown risks. Civil Engineering and Environmental Systems, 2003, 20, No. 2, 83-103.

37. SteWart M. G., Rosowsky D. V. and Val D. V. Reliabilitybased bridge assessment using risk ranking decision analysis. Structural Safety, 2001, 23, No. 4, 397-405.

38. DAS P. C. Development of a comprehensive structures management methodology for the highways agency. Management of Highway Structures. Thomas Telford, London, 1999, pp. 49-60.
39. BRown C. B. Trapped in one's own times: the individual's relationship to education and practice. Civil Engineering and Environmental Systems, 1996, 14, No. 1, 1-14.

40. SiLVERMAN D. The Theory of Organizations. Heinemann, London, 1974.

41. STEPHENS K. Using risk methodology to avoid failures. In Owning the Future (ELMS D. G. (ed.)). Christchurch, New Zealand, Centre for Advanced Engineering, 1998, pp. $303-$ 308.

42. Blockley D. I. and Godfrey P. Doing it Differently: Systems for Rethinking Construction.Thomas Telford, London, 2000.

43. StANDing CommitTeE on Structural SAFETy. Executive Synopsis, $16^{\text {th }}$ Annual Report. Scoss, 2007, pp. 1-11. See www.scoss.org.uk/publictions.asp for further details.

44. Blockley D. I., Elms D. G., Brown C. B and Melchers R. E. Discussion and closure to Ref. 8. Civil Engineering and Environmental Systems, 2008, 25, No. 1, 59-76

45. Melchers R. E., BAKER M. J. and Moses. F. Evaluation of experience. Quality Assurance within the Building Industry. International Association of Bridge and Structural Engineering, Zurich, 1983, pp. 21-38. Report No. 47.

46. LoCKe J. An Essay Concerning Human Understanding (NIDDITCH P. H. (ed.)). Oxford University Press, New York, 1979.

\section{What do you think?}

To comment on this paper, please email up to 500 words to the editor at journals@ice.org.uk

Proceedings journals rely entirely on contributions sent in by civil engineers and related professionals, academics and students. Papers should be 2000-5000 words long, with adequate illustrations and references. Please visit www.thomastelford.com/journals for author guidelines and further details. 